\section{Discussion}

We have previously seen a patient with a chronic aortic dissection in whom bowel ischemia with multiple organ failure developed after a conventional antegrade segmental extent type II TAAA repair with the aid of a femorofemoral bypass and a selective visceral perfusion. We speculated that this complication may have been related to a malperfusion of the visceral organ as a result of the retrograde femoral perfusion. Whenever there is any reason to believe that retrograde perfusion from the femoral artery will cause a malperfusion of the abdominal organs, then a segmental aortic repair, starting from the distal aortic side, appears to be a valid alternative in type II TAAA. Profound hypothermic circulatory arrest with antegrade perfusion is an alternative to this method if proximal aortic clamping is not technically feasible.

\section{References}

1. Svensson LG, Crawford ES, Hess KR, Coselli JS, Safi HJ. Experience with 1509 patients undergoing thoracoabdominal aortic operations. $J$ Vasc Surg. 1993;17:357-70.

2. Coselli JS, LeMaire SA. Left heart bypass reduces paraplegia rates after thoracoabdominal aortic aneurysm repair. Ann Thorac Surg. 1999;67:1931-4.

3. Safi HJ, Miller CC, Yawn DH, Iliopoulos DC, Subramaniam M, Harlin $\mathrm{S}$, et al. Impact of distal aortic and visceral perfusion on liver function during thoracoabdominal and descending thoracic aortic repair. $J$ Vasc Surg. 1998;27:145-53.

4. Kazui T, Komatsu S, Yokoyama H. Surgical treatment of aneurysms of the thoracic aorta with the aid of partial cardiopulmonary bypass: an analysis of 95 patients. Ann Thorac Surg. 1987;43:622-7.

5. Kazui T, Komatsu S, Sasaki T, Yamada O. Graft inclusion technique for thoracoabdominal aortic aneurysms involving visceral branches with the aid of a femoro-femoral bypass. J Cardiovasc Surg. 1987;28:663-70.

\title{
Resection of a pleomorphic carcinoma of the lung invading the descending aorta
}

Yukio Sato, MD, PhD, Noriko Saito, MD, Shunsuke Endo, MD, PhD, Hiroaki Konishi, MD, PhD, Osamu Kamisawa, MD, PhD, Shinichi Otani, MD, Tsuyoshi Hasegawa, MD, and Yasunori Sohara, MD, PhD, Tochigi, Japan

T he concept of pleomorphic carcinoma was introduced by Fishback and colleagues ${ }^{1}$ in a report indicating that most carcinomas with spindle cell or giant cell differentiation are associated with other major subtypes of lung carcinoma, such as squamous cell carcinoma, adenocarcinoma, or large cell carcinoma. In the new World Health Organization/International Association for the Study of Lung Cancer classification system, pleomorphic carcinoma is independent from other major subtypes, and at least a $10 \%$ spindle cell or giant cell component must be present for a diagnosis of pleomorphic carcinoma. ${ }^{2}$ Pleomorphic carcinomas tend to be large, peripheral tumors that often invade the adjacent tissue, ${ }^{1}$ which could pose problems in surgical treatment. Here we present a case of successful resection of pleomorphic carcinoma invading the descending aorta.

\footnotetext{
From the Division of Thoracic Surgery, Department of Surgery, Jichi Medical School, Minamikawachi, Tochigi, Japan.

Received for publication Nov 20, 2003; revisions received Dec 26, 2003; accepted for publication Jan 5, 2004.

Address for reprints: Yukio Sato, MD, PhD, Division of Thoracic Surgery, Department of Surgery, Jichi Medical School, 3311-1 Minamikawachi, Kawachi, Tochigi 329-0498, Japan (E-mail: tcvysato@jichi.ac.jp).

J Thorac Cardiovasc Surg 2004;127:1829-30

$0022-5223 / \$ 30.00$

Copyright (C) 2004 by The American Association for Thoracic Surgery doi:10.1016/j.jtcvs.2004.01.010
}

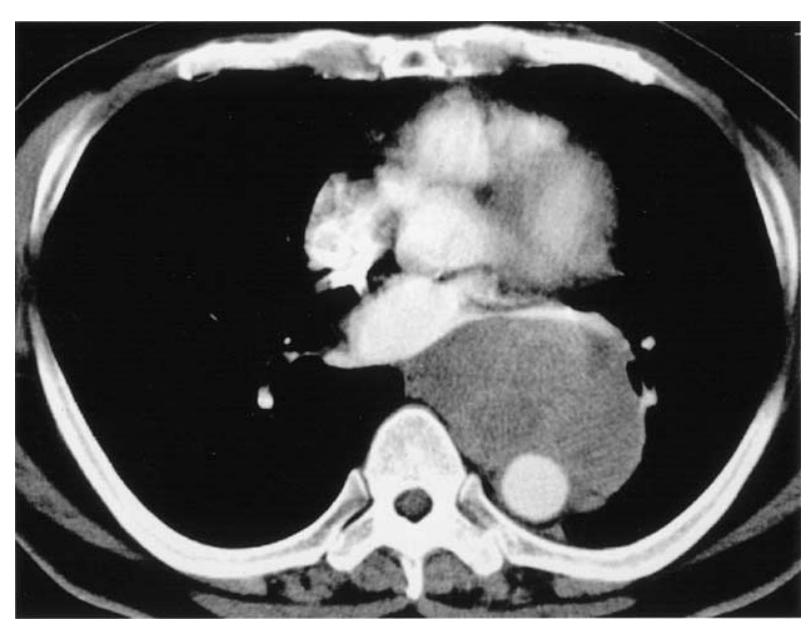

Figure 1. Chest computed tomographic scan shows $9 \times 6 \times$ $10-\mathrm{cm}$ mass enhanced with contrast medium and located in left posterior mediastinum surrounding descending aorta.

\section{Clinical Summary}

A 59-year-old man was admitted to our hospital because of a 3-month history of cough, fever, and back pain. Chest radiography revealed a large mass in the left hilum extending to the posterior mediastinum. Chest computed tomographic scanning (Figure 1) and magnetic resonance imaging revealed a $9 \times 6 \times 10-\mathrm{cm}$ contrast-enhanced mass located in the left posterior mediastinum, surrounding the descending aorta. The contact angle of the tumor to the descending aorta was $270^{\circ}$, and the fat layer between them was not visible. It was therefore suspected that the tumor had 


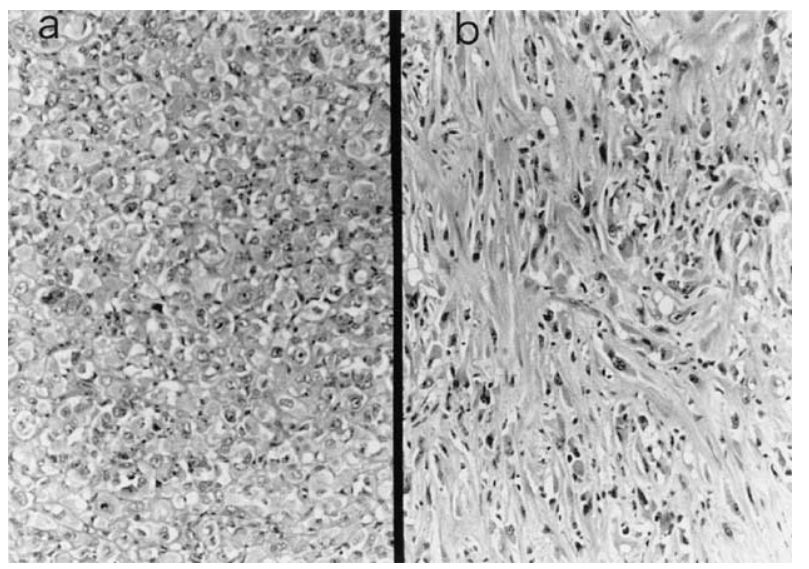

Figure 2. Histopathologic examination revealed tumor to be composed of undifferentiated non-small cell carcinoma (a) and spindle cell (b) components.

invaded the wall of the descending aorta. Histopathologic analysis of a tumor specimen obtained by thoracoscopic biopsy indicated a diagnosis of poorly differentiated adenocarcinoma with sarcomatous component. The clinical stage was cT4 N2 M0, stage IIIb. The patient underwent preoperative radiotherapy (40 Gy) and chemotherapy with cisplatin and vinorelbine ditartrate. Because these treatments had no significant effect and the tumor had unusual histologic type containing a sarcomatous component, the patient underwent surgery.

Intraoperative examination showed that the tumor arose from the left lower lobe and invaded the descending aorta and esophageal wall. Left pneumonectomy with resection of the descending aorta $(15 \mathrm{~cm})$ and partial resection of the esophageal wall was performed under percutaneous cardiopulmonary support (PCPS) established through the left femoral artery and vein. The resected aorta was replaced with a woven Dacron polyester fabric tube graft. The aorta was clamped for 54 minutes, and bypass time was 59 minutes. Operation time was 415 minutes, and intraoperative blood loss was $1750 \mathrm{~mL}$. Histopathologic examination of the resected tumor revealed that it was composed of cytokeratinpositive undifferentiated non-small cell carcinoma and a spindle cell component (Figure 2). It was diagnosed as pleomorphic carcinoma of the left lower lobe. The tumor had invaded the adventitia of the descending aorta and the muscular layer of the esophagus, involving mediastinal lymph nodes (pT4 N2 M0, stage IIIa). The postoperative course was uneventful, and the patient was discharged on postoperative day 28 . He remains free of symptoms without recurrence 1 year after surgery.

\section{Discussion}

Pleomorphic carcinoma typically is seen as a large peripheral lung mass in an elderly man with a history of smoking. ${ }^{1}$ The prognosis of patients with this cancer is controversial. Fishback and colleagues ${ }^{1}$ have reported a poor prognosis relative to that for conventional non-small cell carcinoma and therefore support identification of pleomorphic carcinoma as an independent histologic type in the World Health Organization classification system. ${ }^{2}$ In contrast, Nakajima and associates ${ }^{3}$ have reported similar clinical behaviors and prognoses in pleomorphic carcinoma and non-small cell carcinoma. Additional data on the clinical course of pleomorphic carcinoma is necessary to determine the prognosis of patients with pleomorphic carcinoma.

Pleomorphic carcinomas often invade adjacent tissue. ${ }^{1}$ In our case, computed tomographic and magnetic resonance imaging findings indicated a high probability of tumor invasion into the aortal wall, because such invasion is strongly suspected if the angle of tumor contact with the aorta is more than $180^{\circ}$ or the fat layer between the tumor and aorta disappears. ${ }^{4}$ During aortic resection, blood flow to the abdomen and lower extremities was maintained by PCPS. The patient was positioned in an oblique right lateral position for establishment of PCPS through the left femoral artery and vein. PCPS was effective, and the procedure was performed safely. PCPS has been used for blood oxygenation not only in cardiovascular surgery but also in airway stenting. ${ }^{5}$ It is also considered applicable in combined resection of the descending aorta in lung cancer surgery to maintain blood flow to the abdomen and lower extremities.

Pleomorphic carcinomas can pose problems in surgical treatment, because they tend to be large, peripheral tumors that often invade the adjacent tissue. In this case, pleomorphic carcinoma invading the descending aorta was successfully resected with PCPS.

\section{References}

1. Fishback NF, Travis WD, Moran CA, Guinee DG Jr, McCarthy WF, Koss MN. Pleomorphic (spindle/giant cell) carcinoma of the lung. A clinicopathologic correlation of 78 cases. Cancer. 1994;73:293645.

2. Travis WD, Colby TV, Corrin B, Shimosato Y, Brambilla E. Histological typing of lung and pleural tumours (World Health Organization: International Histological Classification of Tumours). 3rd ed. Berlin: Springer Verlag; 1999.

3. Nakajima M, Kasai T, Hashimoto H, Iwata Y, Manabe H. Sarcomatoid carcinoma of the lung: a clinicopathologic study of 37 cases. Cancer. 1999;86:608-16.

4. Herman SJ, Winton TL, Weisbrod GL, Towers MJ, Mentzer SJ. Mediastinal invasion by bronchogenic carcinoma: CT signs. Radiology. 1994;190:841-6.

5. Ayabe T, Matsuzaki Y, Edagawa M, Asado M, Onitsuka T. A novel interventional therapy using the combination of bilateral bronchial stent dilatation and percutaneous cardiopulmonary support for critical airway obstruction due to metastatic carcinomatous carina. Ann Thorac Cardiovasc Surg. 1999;5:331-5. 